\title{
Commercial Sex Work, Survival Sex, Sexual Violence and HIV/AIDS Prevention in Arumeru District, Arusha Region Of Tanzania
}

\author{
Andre M.N. Renzaho, ${ }^{1, *}$ and Maria Pallotta-Chiarolli ${ }^{2}$ \\ ${ }^{I}$ Senior Research Fellow, School of Public Health Research Evaluation and Policy Cluster, Deakin University; ${ }^{2}$ Senior \\ Lecturer in Social Diversity and Health, School of Health and Social Development, Deakin University
}

\begin{abstract}
:
Objective: To examine the knowledge and practices about HIV/AIDS among female Tanzanian commercial sex workers (CSWs) and assess the contextual dynamics that prevent safer sexual behaviours.

Method: The study used mixed methods and was implemented in two phases. Phase one assessed the knowledge and practices about HIV/AIDS among CSWs. Data were obtained with 54 CSWs, who were selected by using a snowball sampling approach. Semi-structured, face-to-face interviews with the CSWs were undertaken to allow the research participants to describe and discuss their lived realities as they perceive and experience them. In phase two, three discrete focus group discussions, each comprising 6-10 women, were carried out with 26 of the 54 CSWs who were interviewed in phase one.

Results: There was exploitation and inequity in the women's lives due to the multiple and overlapping oppressions of poverty and patriarchy. Sexual violence was framed, legitimised and reinforced by structural and cultural inequities. Such exploitation impacted not only on CSWs' lives as sex workers, but on their previous and/or simultaneous lives as mothers, wives, girlfriends and daughters. The women practised 'survival sex' as CSWs and/or sexual partners of men, and experienced sexual violence from their clients/partners. This violence was either culturally legitimised within a patriarchal framework or manifested itself as 'displaced aggressive sex' by men experiencing marginalisation in socio-economic spheres.

Conclusion: Government health policies and criminal laws regarding sex work, violence against sex workers and domestic/sexual violence against all women need to be critiqued and consistently implemented. Addressing the 'survival sex' of women in Tanzania cannot occur without addressing what the authors call the 'displaced aggressive sex' of men.
\end{abstract}

Keywords: Commercial sex workers, Tanzania, HIV and AIDS, domestic violence.

\section{INTRODUCTION}

In 2005, it was estimated that there were 40.3 million people living with HIV/AIDS (PLWA) and sub-Saharan Africa (SSA) harbours about two third (64\% or 25.8 million people) of the global total number of PLWA despite the continent's population representing just over $10 \%$ of the world population [1]. Of all adults infected by HIV in SSA, 57\% are women while $76 \%$ of infected young people are girls aged $15-24$ years $[2,3]$.

In Tanzania, the first cases of HIV/AIDS were reported in 1983, but the epidemic has spread throughout the general population negatively affecting the nation at household and societal levels by debilitating and depleting economically active sub-populations $[4,5]$. Data from the Tanzanian National AIDS Control Program estimated the national HIV

*Address correspondence to this author at the Senior Research Fellow, WHO Collaborating Centre for Obesity Prevention and Related Research and Training Public Health Research Evaluation and Policy Cluster Faculty of Health, Medicine, Nursing and Behavioural Sciences; Deakin University, 221 Burwood Highway, Burwood 3125; Tel: + 613 92517772; Fax: + 613 9244 6624; Email: andre.renzaho@deakin.edu.au prevalence at $9.3 \%$ in 2004 from $10.5 \%$ in 2001 , but the prevalence ranges from $3 \%$ to more than $44 \%$ dependent upon the region and societal, behavioural and biological factors [6]. Thus, like the rest of SSA, HIV infection is unequally distributed in Tanzania and people are affected differently based on gender, age, and socio-economic class. For example, data from the Tanzanian Ministry of Health suggest that commercial sex workers (CSWs) along the major truck stops and towns have an HIV prevalence of up to $60 \%$, and the HIV prevalence among bar workers varies between $32 \%$ and 50\% [6]. The reported prevalence of HIV among Tanzanian CSWs reflects the findings of other studies in SSA $[7,8]$.

At the societal level, the risk of HIV among CSWs, adolescent girls and young women is exacerbated and framed by complex interweavings of local gendered hierarchies, cultural norms and repressive customary laws, religious beliefs, economic hardships and sexual practices that may uphold and reinforce hegemonic constructions of masculinity and disempowering constructions of femininity. Indeed, factors driving the epidemic are multidimensional and deeply rooted in the very power relations which delineate male and female roles and positions, in terms of both intimate relations or the 
wider society $[9,10]$. For example, in Tanzania, like in other East African countries, polygamy, wife inheritance, female circumcision, early marriage, early initiation of sex among women, young girls having sex with older men, and multiple sexual partners for men are tolerated or acceptable. These practices can place women at risk as they are disempowered to negotiate safer sex and sometimes aggressively coerced into obligatory sex in their relationships and commercial sex transactions.

\section{WOMEN AT RISK AND COMMERCIAL SEX WORK}

The literature states that "women are at risk for HIV because poverty is the primary and determining condition of their lives"[11] p.414. Women's vulnerability in the HIV epidemic in most developing countries is determined by their social, political, and economic subordination as well as poverty-driven sex work as a key survival mechanism [12-15]. In addition, sexual violence including rape is being recognised as a primary determinant of women's vulnerability to HIV/AIDS in many parts of SSA [16-19]. It appears the violence against women, particularly women considered already deviant, dirty or diseased such as CSWs, can be culturally and structurally legitimised and/or it can be a form of 'displaced aggression' whereby factors such as social dislocation, poverty and unemployment can lead to a sense of emasculinization, that is, the loss of what it means to be a man [12]. In this context, a reassertion of 'masculinity' is often attempted through violent action against women, what we call 'displaced aggressive sex'. If a man cannot live up to hegemonic masculinist constructions of economic and social power, the male body and phallocentric sexuality may be seen as the only means by which a form of gendered, sexual power can be gained [17, 20]. Thus, given the poverty of many clients, they may use violent actions such as physical and sexual assaults in order to avoid paying CSWs for sexual services. This behaviour may be condoned as it is directed at an inferior feminine 'other'.

CSWs' vulnerability to HIV/AIDS varies by country and is multidimensional. The first dimension relates to the legislative structure in which they operate. In Tanzania for example, like in many African countries, not only is commercial sex work illegal under the Tanzania Penal Code, it is also unlawful to benefit from commercial sex work's proceeds or to facilitate or assist a person to engage in such activities [21-23]. This means that commercial sex work is non-brothel based and takes place predominantly in bars, guest houses and private homes. Such a practice predisposes CSWs to greater HIV risks than sex workers who operate in brothels [24] because where commercial sex is illegal, the criminalized status of their work means that CSWs are prone to harassment and violence, are less empowered to negotiate safer sex, and are less likely to take legal actions against violence and abuse [25]. The second dimension relates to CSWs not seeking health care from public health services mainly because of their negative experiences in these settings such as being "refused service" and experiencing "public humiliation by health workers" [26] or the location of public health facilities and the inconvenience of their hours of operation [2628]. The last dimension relates to the poverty-driven phenomenon of 'survival sex' where CSWs accept "a client who refuses to use a condom" [29]. Ford and Koetsawang [30] found that some sex workers reported opposition to the use of condoms because "they feared it would delay their clients' ejaculation, thereby prolonging penetrative sexual intercourse and/or oral sex and reducing the total potential number of clients" (p. 407). However, it also needs to be asked to what extent are CSWs coerced or trapped by their clients into not using condoms? [31]

There are some gaps in the current literature, especially the paucity of research into the links between a) the 'survival sex' being undertaken by CSWs due to poverty; b) culturally legitimised and/or 'displaced aggressive sex' that CSWs may experience from clients due to their vulnerable positions as 'survival sex' workers; and c) the implications and consequences in regards to HIV/AIDS and STIs. As Stadler and Delaney [26] put it:

More attention needs to be given to the contextual dynamics that place sex workers at risk. It is thus essential that we have a better understanding of sex workers as people, their interactions with their immediate context, and their divergent and varied reasons for entering sex work... [as well as addressing their locations within] the complex interactions of histories, culture, and political economy (p. 453 )

This paper addresses the above links and contextual dynamics' from the perspectives and standpoint of the CSWs themselves. It is beyond the scope of this paper to consider the perspectives of clients, legal and health authorities, although recommendations to research these perspectives will be made. In the light of the evidence presented in the foregoing discussion, the purpose of this study was three-fold: 1) to document the knowledge and practices about HIV/AIDS among female CSWs in Tanzania; 2) to identify 'the contextual dynamics' that impact upon the 'survival sex' of female CSWs' sexual behaviours, such as the 'displaced aggressive sex' of men as their clients and partners; and 3) to gain some understanding of 'CSWs as people' and their lifeworlds.

\section{METHODS}

\section{Study Area and Population}

The research was undertaken in the Arumeru District, Arusha Region, Tanzania. Located on the foot of Mt Meru which is 11 kilometres east of Arusha Town, the district has a population of 558,986 people spread across six divisions which are: Poli, Mukulati, Kingori, Enaboishu, Mbuguni and Moshono. The major language spoken in the area is Meru. The district has experienced challenges that have impeded an effective HIV/AIDS response. These have included 1) the presence of Tanzanite mines and flower farms in the area, attracting workers from all walks of life and tourists from neighbouring countries and overseas, 2) a high presence of female CSWs, with more than half of all CSWs in the Arusha region living in the Arumeru district because of the high level of tourists, foreign investors, local and foreign mineworkers in the area, 3) a population growth that is higher than any district in the Arusha region, with more than half of the population of Arusha living in Arumeru, and 4) a high level of cultural diversity with repressive and risky cultural and traditional laws that shape and dictate the dynamics of the society. 


\section{Study Design, Sample and Procedure}

The study used a mixed method where both qualitative and quantitative methods were used in two different phases. The research was overseen by a steering committee of 10 people that included 2 CSWs, 2 community representatives, and 6 representatives from the non-government sector assisting people in the Arumeru district.

\section{Phase 1: To Examine the Knowledge and Practices About HIV}

In the first phase, female CSWs were selected using a snowball sampling approach [32]. This is the most efficient method of recruiting hidden and hard-to-reach populations such as CSWs in Tanzania who are prosecuted and harassed by local authorities. Therefore, they tend to identify themselves as barmaids or avoid scrutinisation and identification altogether to prevent persecution by the government. Also, CSWs do not live in clusters and this limits other sampling designs. The initial point of entry involved talking to community counsellors and peer educators who created the links with CSWs. Then, the identified CSW was interviewed and was asked to identify or recommend other CSWs from their networks. The next identified CSW was visited and invited to participate in the study. The process continued until saturation point, that is, no more CSWs could be identified. Prior to data collection, CSWs were told that participation in the study was voluntary: they were free to withdraw their participation at any stage during the study and that data would be presented as aggregate. They were assured that all data provided would be treated with strict confidentiality. In total, 66 female CSWs were identified of whom 54 (81.8\%) consented and were subsequently interviewed. A dozen $(12 / 54=18.2 \%)$ refused to participate because they feared that if the government of Tanzania knew they were CSWs they would be prosecuted.

A structured questionnaire, developed in consultation with the steering committee and community members, was also used to collect data (Summarised in Table 1). The questionnaire had four sections: demographics of factors (age, educational attainment, length of time in the business, prebusiness marital status, number of children, and parental occupation); knowledge about HIV transmission, prevention and risk; sexual practices; and understanding of and barriers to testing services.

\section{Phase 2: To Assess the Contextual Dynamics that Prevent Safer Sexual Behaviours}

Three discrete focus group discussions (FGDs) were carried out with 26 CSWs (out of the 54 CSWs who participated in Phase 1). Each FGD comprised 6-10 women. The FGD guide was developed from the structured questionnaire. Questions that required in-depth information in order to understand the ecological impact on the processes that predispose this sub-population to HIV and AIDS were included in the FGD guide. The FGDs focused on factors that predispose young girls to sex work with particular attention to marriage, underage rape, sexual violence, contextual dynamics of commercial sex work (e.g. negotiating safer sex, prevention methods used by CSWs), and understanding 'CSWs as people' and their lifeworlds.

\section{Operational Definitions}

For the purpose of this study, the definition and legality of marriage was according to the Tanzanian Marriage Act of 1971 and Penal Code [33]. The definition of rape followed that of the Human Rights Watch [34]. Thus, a CSW was defined as a woman who exchanges sex for money or gifts as a livelihood mechanism. To be classified as previously married, a CSW did not necessitate having had a marriage certificate as the Tanzanian Marriage Act recognizes that although marriage registration is obligatory, any non-compliance does not render the marriage void but will only attract a fine. Because polygamy is acceptable within traditional customs, and thus not against the law, both CSWs who were in monogamous and polygamous marriages, with or without any marriage certificate, were considered as previously married. Sexual rape included sexual intercourse without consent and all other forms of sexual activities that are undertaken either with the purpose to harm the woman or without her consent before they got married, during marriage and after marriage [34].

\section{Data analysis}

Data from phase 1 were entered and analysed using SPSS computer software version 13.0 (SPSS Inc. Chicago, III, USA). They were summarised using a descriptive univariate analysis, providing estimates and the associated confidence intervals. Data from Phase 2 were summarised using thematic headings according to both the responses to the FGD guide questions and any themes the women raised themselves. Written contemporaneous notes from FGDs were subjected to manual thematic analysis to identify patterns of experience as well as to identify statements that represent both new emerging ideas and most common threads or persistent words, phrases or concepts that extended throughout the notes [35-37]. The field notes were read and summarized by the first author, and independently summarized by five members of the steering committee. In summarizing the findings, persistent phrases have been used to refer to participants' voices [38, 39]. Quotations were chosen to exemplify differences and commonalities in CSWs' diverse views and experiences or as an illustration of emerging themes.

\section{Results}

\section{Demographic Factors and Health Seeking Behaviours}

Interviewed CSWs have been in the business for an average of 4.1 years (95\% CI: 3.0-5.2 years, min: 4 months, max: 21 years). Almost half of them (48.1\%) were married before becoming CSWs and have on average 3 children from different fathers. At least half of the CSWs (53.7\%) had a child of whom they did not know the father. Almost a quarter of CSWs $(24.1 \%)$ were orphans and a further $31.5 \%$ only had one parent. Almost all of them (94.5\%) had never gone beyond primary school level. Approximately three quarters (71.1\%) of CSWs had a father who was a subsistence farmer, $26.3 \%$ had a father who was self-employed, while $2.6 \%$ had an unemployed father.

Twenty nine CSWs (53.7\%) indicated having had sexually transmitted diseases (STIs) once or more Fig. (1). Of these, more than three quarters (26 CSWs or $89.7 \%$ ) had unprotected sex with clients once or more while still infected 


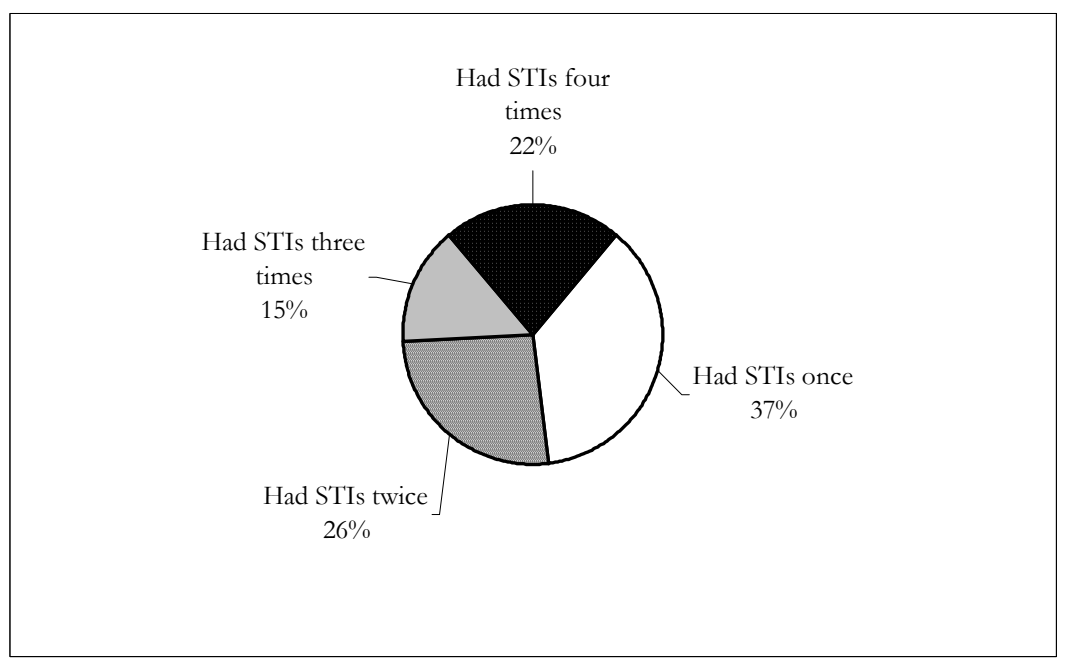

Fig (1). Frequency of STls among CSWs (N=29)

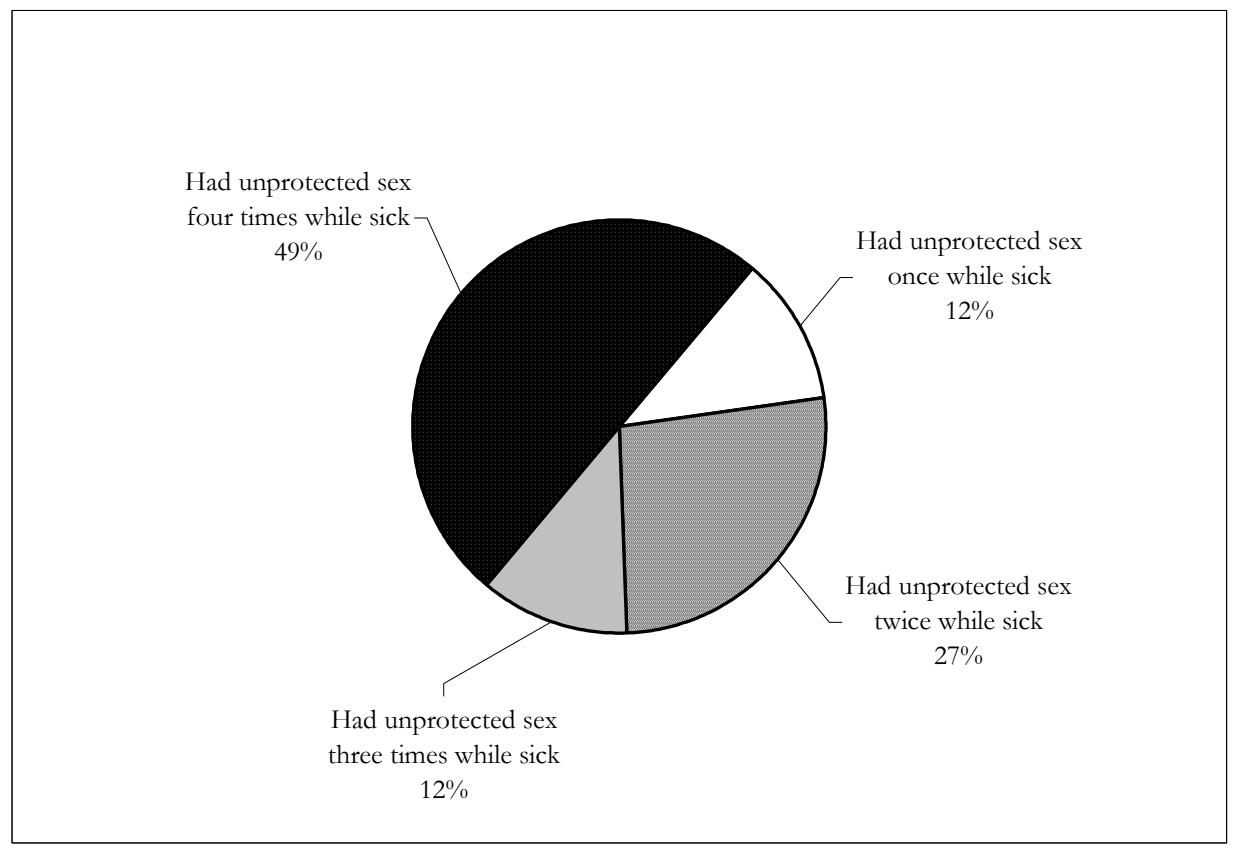

Fig. (2). Frequency of CSWs' unprotected sexual intercourse with clients while suffering from STls (n=26)

Fig (2). Once they contracted STIs, the treatment pattern differed considerably, with $3.4 \%(n=1)$ treating themselves, $72.7 \%(\mathrm{n}=21)$ seeking help from the clinic/hospital, $17.2 \%$ $(n=5)$ being treated by traditional healers and $6.8 \%(n=2)$ doing nothing about it.
Access to Sexual Health Information, Condoms and HIV/AIDS Testing

CSWs obtained information about HIV/ AIDS from various sources, including radio and television (98.1\%), newspa 
Table 1. Knowledge on Prevention, Transmission and Detection of HIV/AIDS

\begin{tabular}{|c|c|c|}
\hline & $\mathrm{N}=54$ & $(95 \% \mathrm{CI})$ \\
\hline Unprotected sexual intercourse & $81.5 \%$ & $(68.5,90.7)$ \\
\hline Transfusion with infected blood & $92.6 \%$ & $(82.1,97.9)$ \\
\hline Sharing non sterile needles with an HIV- infected person & $94.4 \%$ & $(84.6,98.8)$ \\
\hline Mother-to-baby transmission through breast milk & $13.0 \%$ & $(5.4,24.9)$ \\
\hline Using or sharing non sterile material during traditional circumcision & $88.9 \%$ & $(77.4,95.8)$ \\
\hline Using or sharing non sterile material for tattooing and piercing & $55.6 \%$ & $(41.4,69.1)$ \\
\hline Needle-stick injury & $61.1 \%$ & $(46.9,74.1)$ \\
\hline Mosquito (or other insect) bite & $20.4 \%$ & $(10.6,33.5)$ \\
\hline Sharing food with HIV-infected people & $5.6 \%$ & $(1.2,15.4)$ \\
\hline Contaminated clothes & $14.8 \%$ & $(6.6,27.1)$ \\
\hline Sharing toilets/room & $7.4 \%$ & $(2.1,17.9)$ \\
\hline \multicolumn{3}{|c|}{ Correct knowledge on HIV detection: HIV infection can be detected through } \\
\hline Blood test & $94.4 \%$ & $(84.6,98.8)$ \\
\hline \multicolumn{3}{|c|}{ Misconception about HIV detection: HIV infection can be detected through } \\
\hline Taking injection with sterile needle & $81.5 \%$ & $(68.6,90.7)$ \\
\hline \multicolumn{3}{|l|}{ Awareness of risky behaviours: Know that } \\
\hline People with STls are at increased risk of HIV/AIDS infections & $50.0 \%$ & $(36.1,63.9)$ \\
\hline Polygamy/multiple partners increases the risk of HIV/AIDS infections & $88.9 \%$ & $(77.4,95.8)$ \\
\hline
\end{tabular}

pers and magazines (32.6\%), friends and relatives $(79.6 \%)$, community health centres $(59.3 \%)$, seminars and workshops $(57.4 \%)$, churches and mosques $(55.6 \%)$, posters and leaflets $(51.9 \%)$, and school teachers $(22.2 \%)$. The increased access to information resulted in increased knowledge about HIV/AIDS among CSWs Table 1.

Almost all $(93 \%)$ of them knew 3 or more correct ways of HIV transmission while $81.5 \%$ knew 3 or more ways of HIV prevention. Of concern was the high level of misconceptions about HIV/AIDS with $33.3 \%$ of interviewed CSWs found to hold 3 or more myths and misconceptions about HIV/AIDS. Most interviewed CSWs also knew where condoms were sold. Nominated places included shops and boutiques $(94.4 \%)$, pharmacies $(85.2 \%)$, clinics and hospitals $(83.3 \%)$, bars, guest houses and hotels $(68.5 \%)$, family planning centres $(63.0 \%)$, community counsellors $(51.1 \%)$, mar- kets $(18.5 \%)$, and friends (16.7\%). Despite the increased availability of condoms, they are unaffordable for most CSWs (Table 2).

Data on condom use in the project area depicted an ambivalent pattern (Table 2). One in $10 \mathrm{CSWs}(11.1 \%)$ reported having never used condoms. Of those who ever used a condom $(n=48), 68.8 \%(n=33)$ used condoms the last time they had sexual intercourse with a client. More than three quarters $(83.4 \%)$ of condom users reported using condoms occasionally while $16.6 \%$ reported always using condoms at their own insistence and not the client's. The main reasons for using or not using a condom are summarised in Table 2. Despite CSWs being subjected to multiple risk factors, they were less likely to undertake an HIV test due to numerous reasons summarised in Table 3 . 
Table 2. Practices Related to Sexual Activities

\begin{tabular}{|c|c|c|}
\hline & $\%$ & $95 \% \mathrm{C})$ \\
\hline $11-17$ years & $51.9 \%$ & $(37.8,65.7)$ \\
\hline 18 years and older & $44.4 \%$ & $(30.9,58.6)$ \\
\hline 12 clients or less per week & $24.1 \%$ & $(13.5,37.6)$ \\
\hline 13-20 clients per week & $22.2 \%$ & $(12.0,35.6)$ \\
\hline $21-25$ clients & $35.2 \%$ & $(22.7,49.3)$ \\
\hline 26 clients or more & $18.5 \%$ & $(9.3,31.4)$ \\
\hline Of those who ever used a condom, used a condom the last time they had SI & $68.5 \%$ & $(54.5,80.5)$ \\
\hline \multicolumn{3}{|l|}{ Reasons for using a condom $(\mathrm{N}=37)$} \\
\hline Avoid getting the disease & $100.0 \%$ & - \\
\hline Avoid pregnancy & $62.2 \%$ & $(48.7,75.7)$ \\
\hline Avoid giving the disease & $40.5 \%$ & $(27.6,55.0)$ \\
\hline Pressure from partner & $2.7 \%$ & $(0.1,9.9)$ \\
\hline \multicolumn{3}{|l|}{ Reasons for not using a condom among non-users $(\mathrm{N}=17)$} \\
\hline Don't trust condoms & $11.8 \%$ & $(1.5,36.4)$ \\
\hline Trust my partner/clients & $5.9 \%$ & $(0.1,28.7)$ \\
\hline \multicolumn{3}{|l|}{ Practice $(\mathrm{N}=54)$} \\
\hline Reporting having had sexual intercourse before getting married & $89.3 \%$ & $(77.2,95.9)$ \\
\hline Reporting that it is normal to have extra marital affairs & $88.9 \%$ & $(77.4,95.8)$ \\
\hline Reporting having friends involved in homosexuality & $50.2 \%$ & $(36.1,63.9)$ \\
\hline
\end{tabular}

Displaced Aggressive Sex, Women's Sexual Practices, and the Impact of Poverty and Patriarchy Before Becoming CSWs

Data presented in Table 2 suggest that CSWs' vulnerability to HIV/AIDS did not begin when they began sex work. Some of the interviewed CSWs had sexual intercourse as early as 5 years old, and this occurred in the form of rape by family members or family friends. As the demographic data show. almost half the CSWs were or had been married. They indicated during FGDs that they were forced to marry at a very young age before venturing into the commercial sex industry. They became victims of domestic/sexual/emotional violence and either eventually divorced their husbands or were divorced by their husbands. Thus, they became CSWs due to hardship post divorce, as they could not afford to live alone without a breadwinner or a job. In other words, sex work as 'survival sex' occurred after the woman had already been subjected to sexual violence and coercion. In providing a typical example of the intersecting factors of poverty and patriarchal power that lead to 'survival sex' work, a 34 year-old research participant, who reflected the most common experiences put forward by CSWs, explained: 
Table 3. Reasons that CSWs give for not undertaking an HIV test

\begin{tabular}{|c|c|c|}
\hline Reasons & $\mathbf{N}=54$ & $(95 \% \mathrm{CI})$ \\
\hline Rejection and discrimination by the community and family if the test becomes positive & 85.2 & $(72.9,93.4)$ \\
\hline Not being informed: people do not understand the importance of HIV/AIDS testing & 29.6 & $(18.0,43.6)$ \\
\hline Lack of support pre and post testing & 27.8 & $(16.5,41.6)$ \\
\hline Fear of enhanced death e.g. blood pressures, depression, shock and would commit suicide & 24.1 & $(13.5,37.6)$ \\
\hline Absence of country guidelines for HIV testing & 14.8 & $(6.6,27.1)$ \\
\hline Absence of hospital guidelines & 9.3 & $(3.7,20.3)$ \\
\hline
\end{tabular}

"When I gave birth my husband could not afford to buy me food required to produce breast milk. My neighbour provided me with good food to feed my child and myself and I rewarded him with sex but most of the time he wanted anal sex. When my husband knew about this he left me. However, before I was kicked out the house, my husband demanded anal sex too. It all started when I was breast feeding and he suggested that my vagina was "dirty" and when a wife is breast feeding the couple should only have anal sex. The problem is when we did it, it was painful and when I consulted some of the known community counsellors for advice, they told me that if I continue to have anal sex the next time I become pregnant the baby will come by the anus when I give birth. So I had no choice but to leave the husband. Life became difficult and I became a CSW. Now I do it for money".

The overwhelming reason provided by CSWs for divorcing their husbands was that the latter wanted anal sex but they had been led by community health workers to believe that if they had anal sex they would not have a normal delivery if they became pregnant (i.e. the child would come through the anus rather than the vagina). Thus, they opted to run away from their husbands. Alongside the coercion women experienced to participate in a sexual practice they did not want and/or found painful, and its basis in cultural tenets about vaginas being "dirty" during breastfeeding, what is also disturbing is the perpetuation of cultural myths about anal sex and childbirth by community health workers!

Other reasons CSWs gave for divorcing husbands also highlight the prevalence of emotional, physical and sexual violence, subjugation and disempowerment of the women within their marriages and extended families. Here are some examples of what some research participants discussed:
When I became pregnant my husband denied being the father of the to-be-born child saying that I cheated on him, that I slept with my neighbour and that the latter was the father of the child. He left me.

$\mathrm{xxx}$

"My husband was married and lied to me that he was not married when he met me. After we married I later learned that he was still living with his first wife and I left him".

$\mathrm{XXX}$
"my then husband was educated and had a bachelor degree but I was not educated. I did not finish primary school. My family-in-law re- fused to accept me saying that I could not enter- tain guests as I could not speak English. They forced me out of the marriage".

At a very young age, CSWs were tutored by their often older husbands that domestic violence was an expression of love. Wife battering as an expression of love has been condoned and practised by some ethnic groups over generations across Tanzania. As a CSW explained:

$\mathrm{xxX}$

\begin{abstract}
"If a woman is not beaten she feels like she is not loved by her husband and that the husband is cheating on her. It is culturally satisfying if the woman is beaten such as in Curia and $\mathrm{Mu}$ soma tribes. The woman will do her best to upset her husband in order to be beaten. Such a provocation includes deliberately cheating on him, not feeding him, drinking, or leaving children alone".
\end{abstract}

Another reason raised by some of the women for divorcing their husbands was the homosexuality or bisexuality of 
Table 4. CSWs Reporting Certain Behaviours and Practices $(\mathrm{N}=54)$

\begin{tabular}{|c|c|c|}
\hline \multicolumn{1}{|c|}{ Factors } & \% & (95\% CI) \\
\hline \hline Reporting that if they get a good job, they will leave the business & 79.6 & $(66.5 .89 .3)$ \\
\hline That clients prefer not to put a condom on as they believe it reduces their sexual pleasure & 77.8 & $(64.4,88.0)$ \\
\hline That insistence on wearing a condom is not a priority so long as they get money to buy food & 68.5 & $(54.5,80.5)$ \\
\hline That clients pay extra money to have unprotected sex & 66.7 & $(52.5,78.9)$ \\
\hline Reporting that they are in this business because it is easy money and pays well & 66.7 & $(52.5,78.9)$ \\
\hline Reporting having clients asking for anal sex & 46.3 & $(32.6,60.4)$ \\
\hline Reporting having clients who are married & 37.0 & $(24.3,51.3)$ \\
\hline Reporting having had unprotected anal sex & 31.5 & $(19.5,45.6)$ \\
\hline Reporting that some clients bring condoms with them & 22.2 & $(12.0,35.6)$ \\
\hline Reporting having clients who are polygamous & 20.4 & $(10.6,33.5)$ \\
\hline
\end{tabular}

the men. This is exemplified by the experiences of a 29 yearold sex worker in the following:

$\mathrm{xxx}$

\begin{abstract}
"My husband used to invite his friend over. He used to tell me that this friend was a business partner and each time he visited they would go in our bedroom. I was told not to disturb them as they were going through business financial statements. However, one day I was shopping with a friend and I told her about my then husband and his business partner. This friend told me that they must be up to something else and encouraged me to ambush them one day to see exactly what kind of financial statements they were discussing. She empowered me saying that after all my husband's business is also my business and I had the right to know what exactly was going on. A week after my conversation with her, the so called business partner visited us at around 2 PM, they did the usual routine and 15 minutes later I ambushed them in the bedroom. I found them in plain action. How naive was I? It was the first time I realized that men can have sex with men. However, my husband convinced me not to leave him as he guaranteed me that he was only experimenting with it and he did not like it at all. He promised he would never do it again. Later on other things came to complicate our marriage."
\end{abstract}

\section{'Survival Sex' as CSWs, and the Links Between Poverty, Patriarchy and Unprotected Sex}

CSWs stated that the preference for unprotected sex is a serious issue they confront on a daily basis (Table 4). Clients often refuse to use a condom to the point of being violent. As one CSW pointed out: "we usually convince clients to use a condom and negotiate the price accordingly [usually cheaper if a condom is used]. But once in the bedroom we are beaten to accept unprotected sex". In addition, half of the interviewed CSWs (46.3\%) have had clients asking for anal sex and $31.5 \%$ of the CSWs reported having had unprotected anal sex. Factors that relate to the displaced aggressive sex CSWs experience from clients due to their vulnerable positions is summarised in Table 4. However, the area of anal sex remains a taboo not to be spoken about. CSWs indicated that most of their clients are married men wanting unprotected anal sex at any cost. During FGDs, one CSW, who represented the views of many, observed:

\begin{abstract}
"most of our clients come asking for or wanting anal sex. They usually negotiate for vaginal sex but once in the bedroom they force us to have anal sex and if we refuse we will be beaten and will not be paid". As another CSW stressed "it is easy to suggest that mine workers are used to having anal sex among them while in the mountains and that when they are in town they want to continue the trend. The truth is most Tanzanian men like anal sex".
\end{abstract}

CSWs reported having standardized rates according to whether or not a condom is used and according to the sex preference of the client. During FGDs, the following prices were quoted: sex without a condom whether vaginal or anal: 3,000-10,000SHT (3-10 US\$) for full service; sex with condom: 500-2000SHT ( 0.5 to 2 US\$) and 'Chamusha Maharage' (translated as 'heating the beans' meaning quick and cheap sex): 200 to 500 SHT (0.2 to 0.5 US\$). Chamusha Maharage was practised by CSWs who were desperate for money to buy food and did not include any negotiation about using condoms. This cluster represents CSWs who were prone to gang rape. CSWs commented on how the price of a packet of condoms is "far greater" than the payment they receive for the sex work. They commented: "the price of a packet of three condoms is far greater than the price we receive for Chamusha Maharage". In discussing clients' refusals to use a condom, they added: "most of our clients like 
Nyama kwa Nyama as they believe that putting on a condom is not different from masturbating". As one CSW eloquently put it: "they [clients] often negotiate to pay 10,000 SHT [10US\$] for unprotected sex but after the act they beat us and end up paying us 3,000 SHT [3US\$] and sometimes as low as 500SHT [0.5US\$]”. In her support, another encapsulated the experience by adding: “... most clients often tend to negotiate unprotected sex with us but we end up being raped afterward by 10-15 men taking turn one after the other".

\section{The Links Between Abusive Working Environments and HIV Prevalence in CSWS}

The violence again CSWs was also facilitated by their working environments. As one CSW testified during a FGD:

\begin{abstract}
"we usually finish work between 10 and 12 midnight. We are usually raped on our way back home. Because in most cases the rapists do not wear condoms, most of us have been raped more than three times and all of us who have children [48.1\%] have had at least 1 child of whom we do not know the father. To reflect this ${ }^{2}$ the most common names we give our children are 'Zawadi meaning 'present', 'Shida' meaning 'difficulty/suffering', 'Sikujua' meaning 'I did not know', 'Sikuzani' meaning 'I did not expect it', and 'Tabu/ Matatizo' meaning 'hardship/problem".
\end{abstract}

In the case of any infection, CSWs talked about how they are always blamed and abused by the clients:

$\mathrm{xxx}$

\begin{abstract}
"when we force or convince clients to use a condom, they will deliberately be rough during sex in order to break the condom because once the condom is broken they will blame us for having infected them. Then clients will refuse to pay us saying they will use the money to pay for their medical bill for STD check up... Unfortunately, most of the time clients are the one infecting us. But we need the money and they are sexually virulent, we have no choice".
\end{abstract}

What was also disturbing was the fear of prosecution by police which prevented CSWs from reporting the violence and theft of clients:

\begin{abstract}
"If we insist on payment after the sexual act, clients follow us, beat us and take the money back. We cannot do anything as we will be reported to the police. If we are reported to the police, we will be prosecuted".
\end{abstract}

\footnotetext{
${ }^{1}$ https://services.exchange.deakin.edu.au/owa/?ae=PreFormAction\& amp; $\mathrm{a}=$ ReplyAll\&amp;t=IPM.Note\&amp;id=RgAAAAAbdFx1 VnF2QZ9H0Ak y\%2fAIrBwA8npyoB1eoQbBJFsgOeNyAAAABYf6AAA8npyoB1eoQbBJ FsgOeNyxAAA4EQTCAAAJ\#_ftnref1 Translated as "meat on meat" to describe unprotected sex. The official price set by CSWs is $10,000 \mathrm{TSH}$ (10US\$).

${ }^{2}$ In African cultures, names are given in memory of something e.g. to reflect the environment the child was born in or to describe something related to the family.
}

The exploitation of CSWs happens at all levels in the community. For example, bar or hotel owners were discussed as taking advantage of the fact that CSWs are not tolerated by both the civil society and Tanzanian authorities. This persistent belief that sex work is a criminal activity means CSWs risked arrest and continuous harassment from police and other legal authorities and were thus very reluctant to report rape and other forms of violence. A 22 year old CSW explains the collusions between hotel manager, client and police authorities:

\begin{abstract}
"In most cases, the hotel manager will ask us to meet a client in a room or ask us to bring beverages to clients in their rooms. Once there, we are taken by force, often raped and sometimes beaten. When we ask clients as to why they are raping us, the clients usually say that the hotel manager is aware of the act and they have already paid him, thus we end up not being paid... we are left powerless as we could be reported to the police as being prostitutes and get arrested. The sexual act is often unprotected and painful".
\end{abstract}

Then it is police authorities who are complicit. In the following, an 18 year old CSW explained her ordeal

$\operatorname{xxx}$
"One man negotiated sex with me but I did not realize he had brought his friends along. Half- way through the sexual act his friends came and followed-on after him, they were about between 10 and 15 men and I ended up in hospital. When I reported the event to the police, no action was taken and instead the police blamed me saying that I must have unpaid debts, that's why I was being punished. This kind of police behaviour has happened to most of us. The consequence of complaining to and inaction by the police means that the next time one of gang rapists come across the sex worker that complained she would be punished severely. The punishment of- ten happens in three stages. First you will again be gang raped. Each of the group takes turns starting with vaginal sex. Then they would fol- low on with anal sex and finish off by forcing a whole bottle of beer in the anus and a piece of cloth in the mouth until you lose conscience. This has led to most sex workers unwilling to complain when they are gang raped, forced into unprotected sex or anal sex".

Finally, family members can be complicit too. The following 21 year-old CSW explained:

$\mathrm{XXX}$
"My aunt brought me here to help with domes- tic work. Few days later she told me she brought me for commercial sex and started tak- ing appointments with clients on my behalf. She often takes the money and does not pay me a salary as she states that she pays my accommo- dation, feeds me and pays my medical cost if I 
become sick. As a result, I end up having cheap sex outside my aunt's business for as low as 500SHT [0.5US\$] to get money to buy clothes and look after my hair. For example, to get money to do my hair I require to sleep with 10 different men to get 5000 SHT [5US\$] in addition to the appointment made by my aunt. But if she knows that I am having extra business outside her own, I will be in serious trouble".

\section{DISCUSSION}

This study has documented the knowledge and practices about HIV and AIDS among female CSWs to identify 'the contextual dynamics' that impact upon the 'survival sex' of female CSWs' sexual behaviours. The study found a paradox characterised by adequate knowledge about HIV/AIDS on one hand, and a high level of misconception about HIV transmission on the other. The study also found a high level of culturally, structurally and poverty-induced exploitation and mistreatment of CSWs, making it difficult for them to adopt safer sexual practices and establish safer working environments. These findings suggest that existing HIV and AIDS programs, while effective in raising awareness, fail to dispel HIV-related myths and to ensure the dignity of CSWs is preserved in their families, communities and with legal authorities.

Current government statistics in Tanzania have not been able to depict homosexuality or bisexuality as a potential source of HIV infection [40]. Such statistics are not supported by these findings. Furthermore, in addition to the emotional betrayal and lack of control women experienced after discovering their partners were having sex with other men, what is of concern here is the women's lack of knowledge about sexual diversity and the reality that some men have sex with men, and of course, consequently, a lack of knowledge about the sexual health implications for their husbands and themselves. Importantly, what is more risky is the continuing men's preference for unprotected sex at any cost, often characterised by violence in the form of forced group sex or gang rape. In the literature, this behaviour has been linked to the cultural construction of gender roles. In their study, ten Brummelhuis and Herdt [41] found that the aversion to condom use is linked to dominant constructions of a sexually uncontrollable and virile masculinity [20]. Wearing a condom is a rationalization or regulation of one's sexual drive as well as showing consideration to one's female partner, which betray or diminish one's masculinity. These constructions of masculinity are linked to the abuse male clients may show toward CSWs. If dominant patriarchal social values hold that to be a woman is to be able to control one's sexual drive and be ignorant about sex until one gets married and conforms monogamously to the husband's sexual desires, CSWs fall outside of this construction of a "good" woman. Therefore, as they are less of a woman, abuse and violence toward them are justified.

Poor women involved in transactional sex are stripped of their power to control and protect their own bodies, and negotiate who has access to their bodies and how access to their bodies is determined. Male clients may use physical, psychological and sexual violence and humiliation to demonstrate their power to the woman, but more importantly to themselves, to their male peers and other powerful males to whom they may feel inferiorised. Wood's ethnographic work in South Africa describes how group rape or collective sexual coercion (known as "streamlining") is often justified as a means men use to correct the behaviour of girls or women viewed as transgressive or disrespectful to the authority or sexual rights of men [42]. "Streamlining" was used to discipline the woman and humiliate her while reinforcing group bonding through her being "shared" with the man's male friends. Wood also points to the "politics of legitimation" deployed by these men:

While admitting that women 'do not like it', many young men insisted that 'streamlining' was not 'rape', deploying arguments related to tactics used (often trickery and coercion rather than outright violence), the lack of voiced refusal on the target's part, and the fact that the target 'deserved it' [42] p.310.

Wood also draws the link between "streamlining", "patriarchal gender ideologies" and what we call "displaced aggressive sex' by situating them within "a context where working-class African men have long been marginalized.... historically disenfranchised and profoundly disadvantaged by the exploitative migrant system that defined the colonial economies" [42] p.304. Certainly, as women are increasingly repelled by "traditional" male attitudes and mores and seeking more independence domestically, economically and sexually, this "empowerment" of women is threatening to many men. Other researchers such as Silberschmidt [12] and Masenja \& Urassa [43] explore the escalation of gender antagonism and domestic/sexual violence as men's position as heads of households is challenged, and men experience economic marginalization: "A man's honor, his reputation, his ego, and his masculinity are severely threatened if he cannot control his wife" [12]. Some of this abuse and maltreatment are then delivered to sex workers as "bad" women who are deserving of such treatment.

Other researchers such as Epstein [44] believe there are links between explanations that draw attention to colonial cultures and explanations that refer back to cultural practices of male bonding over sex with women that date back to precolonial society where a man's status depended upon his ability to control women. Chiefs and other economically elite men would allow other men to sleep with their wives. This was considered statesmen-like behavior. Epstein believes that contemporary gang rape may be a violent reprise of this male-bonding tradition within a changing economic, gendered and sexual context.

The resilience of a precolonial construction of masculinity emphasizing virility and a denial of health concerns persists in contemporary cultural narratives regarding AIDS. A rural woman retold a saying she heard men using, "If you do not die of AIDS you are not a man" [45]. Current legislation says rape is illegal but the actual conviction rate is very low due to patriarchal cultural belief systems and codes within which women fear further reprisals from men in collusion: those who are committing the crimes, and those who are authorities meant to police the criminals [44]. Thus, our research points to how CSWs have become victims of their own working environment. Given the global, local and historical socio-economic and gendered constructions within which their clients are marginalized and operating, CSWs' 
working environments are not enabling as far as HIV/AIDS prevention is concerned. Male counterparts are culturally absolved of blame for the high incidence of HIV infection but women are "othered" as loose, immoral, dirty, promiscuous[46], thus deserving the punishment.

Further research is required to explore why CSWs continued to have unprotected sexual intercourse with their clients while infected. It may be that there was an element of revenge on society and anger for being exploited. Research is required to examine if this identified pattern is national, as it constitutes a very serious problem. In addition, given this study was carried out only in Arumeru district, the findings cannot be generalised across the nation. Further research is required to establish the extent to which CSWs' experiences observed in the Arumeru district reflect a national pattern.

\section{CONCLUSION}

In support of previous studies, the cultural legitimization of violence toward women by men and the legislation vacuum that continues to plague African countries impacted upon the research participants' sexual practices. Consistent with Epstein's observation "empowering women, without addressing the attitudes of the wider society", has the risk of creating "empowered women who antagonize men, and thus they play right into the rapists' hands" [44] p.3. The Western middle class discourse of "informed choice" used in HIV prevention cannot be achieved if men, constructions of masculinity and their bases and protection within political, legal, socio-economic and cultural forces are omitted from policy development, programming and practice [12]. There is a need to move away from traditional HIV/AIDS preventative programs and embrace strategies that situate the 'survival sex' of CSWs alongside and interwoven with the 'survival sex' of all women experiencing the multiple oppressions of poverty, patriarchy and violence. Government health and economic policies and criminal laws regarding sex work, violence against CSWs and domestic/sexual violence against all women need to be critiqued and consistent. There is a need to instigate brothel-based healthcare to provide STI treatments and counselling, and to ensure these are protected by local legal authorities. In this way, accessibility and efficacy are achieved as well as transforming the image of the brothel from sites of "dirt and disease" into "healthy brothels" [26]. Clinical services provided on site and clinical staff can introduce new forms of female controlled HIV prevention methods such as female condoms that sex workers can use with clients who insist on unprotected sex. These clinics could also be places where male clients feel more comfortable in consulting staff for advice on sexual health concerns.

\section{AUTHORS' NOTES}

At the time of the study, Andre Renzaho was employed at World Vision Australia as Program Quality Advisor. The study design, data collection and analysis, presentation of the results including the background to the paper were undertaken by Andre Renzaho. Maria Pallotta-Chiarolli discussed and contextualised the study findings and significantly reviewed the paper in terms of content and structure. Both authors have read and approved the manuscript. The authors declare that 1) this is an original manuscript and it has not been submitted to or published in another journal, and 2) there has not been any financial or other relationship that might lead to a conflict of interest.

\section{REFERENCES}

[1] Joint United Nations Programme on HIV/AIDS, World Health Organisation. AIDS epidemic update. Special Report on HIV Prevention. Geneva: UNAIDS 2005.

[2] Ali-Dina A. Africa: AIDS Report. AfricaFocus Bulletin (cited 12/02/2006). Available from: wwwafricaupennedu/afrfocus/afrfocus $120304 \mathrm{html}$

[3] Joint United Nations Programme on HIV/AIDS. Report on the global AIDS epidemic. Geneva: UNAIDS 2004.

[4] Tanzania Commission for AIDS. HIV/AIDS IN TANZANIA (cited 12/11/2006). Available from: http://www.tanzania.go.tz/hiv _aids.html

[5] World Health Organisation. United Republic of tanzania: Summary country profile for HIV/AIDS treatment scale-up. WHO Country Office for the United Republic of Tanzania and the WHO Regional Office for Africa (cited 20/01/2007 2005) Available from http://www.who.int/hiv/HIVCP_TZA.pdf

[6] National AIDS Control Programme. National guidelines for the clinical management of HIV and AIDS: Ministry of Health, The United Republic of Tanzania 2005.

[7] Morison L, Weiss HA, Buve A, et al. Commercial sex and the spread of HIV in four cities in sub-Saharan Africa. AIDS 2001; 15 (suppl 4): S61-S9.

[8] Hawken M, Melis R, Ngombo D, et al. Part time female sex workers in a suburban community in Kenya: a vulnerable hidden population. Sex Transm Infect 2002; 78: 271-3.

[9] Baylies C. Perspectives on gender and AIDS in Africa. In: Baylies C, Bujra J, the Gender and Aids Group, Eds. AIDS, Sexuality and Gender in Africa: collective strategies and struggles in Tanzania and Zambia London and New York 2000: Routledge.

[10] Baylies C, Bujra J. AIDS, sexuality and gender in Africa. Collective strategies and struggles in Tanzania and Zambia. London 2000: Routledge.

[11] Ward MC. Poor and Positive: Two Contrasting Views from Inside the HIV/AIDs Epidemic. Pract Anthropol 1993; 15(4): 59-61.

[12] Silberschmidt M. Poverty, Male Disempowerment, and Male Sexuality: Rethinking Men and Masculinities in Rural and Urban East Africa. In: L. O, Morrell R, Eds. African Masculinities: Men in Africa From The Late Nineteenth Century to The Present. New York: Palgrave Macmillan 2005.

[13] Bujra J. Rethinking anthropology: the study of AIDS. In: ten Brummelhuis HH, G., ed. Culture and Sexual Risk: Anthropological Perspectives on AIDS Sydney: Gordon and Breech 2002.

[14] Sabatier R. Women and AIDS: Strategies for the Future. Proceedings of the meeting on Women and HIV/AIDS. Ottawa, Canada: CIDA 1990.

[15] Carovano K. More Than Mothers and Whores: Redefining the AIDS Prevention Needs of Women. Int J Health Ser 1991; 21: 13142.

[16] Andersson N, Ho-Foster A, Matthis J, et al. National cross sectional study of views on sexual violence and risk of HIV infection and AIDS among South African school pupils. BMJ 2004; 329(7472): 952-7.

[17] Kistner U. Gender-based Violence and HIV/AIDS in South Africa: A literature Review, CADRE/Department of Health 2003.

[18] Karamagi CA, Tumwine JK, Tylleskar T, Heggenhougen K. Intimate partner violence against women in eastern Uganda: implications for HIV prevention. BMC Public Health 2006; 6: 284.

[19] Walker L, Reid G. Men Behaving Differently. Cape Town: Double Storey 2005.

[20] Connell RW. Masculinities. Berkeley: University of California Press 1995.

[21] Ferguson A, Morris CN. Mapping transactional sex on the Northern Corridor highway in Kenya. Health Place 2007; 13(2): 504-19.

[22] Changalucha J, Gavyole A, Grosskurth H, Hayes R, Mabey D. STD/HIV intervention and research programme Mwanza Region, NW Tanzania. Sex Transm Infect 2002; 78: 91-6.

[23] Haram L. AIDS and risk: The handling of uncertainty in northern Tanzania. Cult Health Sex 2005; 7(1): 1-11.

[24] Hugo G. Population Mobility and HIV/AIDS in Indonesia, Jakarta, Indonesia: ILO, 2001, p. 150. 
[25] Arnott J. Sex workers and law reform in South Africa. HIV AIDS Policy Law Rev 2004; 9(3): 78-80.

[26] Stadler J, Delaney S. The 'healthy brothel': The context of clinical services for sex workers in Hillbrow, South Africa. Cult Health Sex 2006; 8(5): 451-63.

[27] Muyinda H, Seeley J, Pickering H, Barton T. Social aspects of AIDS-related stigma in rural Uganda. Health Place 1997; 3: 143-7.

[28] Lawless S, Kippax S, Crawford J. Dirty and diseased and undeserving: the positioning of HIV positive women. Soc Sci Med 1996; 43: 1371-7.

[29] Collins J, Rau B. AIDS in the Context of Development. UNRISD Programme on Social Policy and Development, Paper No. 4, UNRISD and UNAIDS 2000.

[30] Ford N, Koetsawang S. The socio-cultural context of the transmission of HIV in Thailand. Soc Sci Med 1991; 33(4): 405-14.

[31] Wojcicki J, Malala J. Condom use, power and HIV/AIDS risk: sexworkers bargain for survival in Hillbrow/Joubert/Brea, Johannesburg. Soc Sci Med 2001; 53: 99-121.

[32] Kowalewski MR. Double Stigma and Boundary Maintenance: How Gay Men Deal With AIDS", J Cont Ethnogr 1988; 17(2): 211-28.

[33] United Republic of Tanzania. The Tanzanian Marriage Act of 1971 and Penal Code (cited: 12 March 2004). Available from www.law.emory.edu/ifl/legal/tanzania.htm\#table

[34] Human Rights Watch. Seeking protection: addressing sexual and domestic violence in Tanzania's refugee camps. New York: Human Rights Watch 2000.

[35] Taylor SJ, Bogdan R. Introduction to qualitative research methods: the search for meanings. New York: John Wiley and Sons 1984.

[36] Spradley J. The ethnographic interview. New York: Holt, Rinehart and Winston 1979.
[37] Constas MA. Qualitative analysis as a public event:the documentation of category development procedures. Am Edu Res J 1992; 29: 253-66.

[38] Holloway I. Qualitative writing. In: Holloway I, ed. Qualitative research in health care. Beckshire: Open University Press 2005; 270-84.

[39] Emden C. A conversation with Margarete Sandelowski and Philip Darbyshire: issues in qualitative inquiry. Nurs Inq 1997; 4: 138-41.

[40] Ministry of Health. Tanzania National HIV/ AIDS control Program: The United Republic of Tanzania 2001.

[41] ten Brummelhuis H, Herdt G. Culture and Sexual Risk: Anthropological Perspectives on AIDS. Sydney: Gordon and Breach Publishers 1995.

[42] Wood K. Contextualizing group rape in post-apartheid South Africa. Cult Health Sex 2005; 7(4): 303-17.

[43] Masanja P, Urassa E. "The Marginalisation of Men". Paper presented for the Conference Population Reconsidered, Swedish Development Agency (SIDA), Harare 1993.

[44] Epstein H. AIDS and Africa's Hidden war, The Virginia Quarterly Review, 2006 (Cited 12/01/2007. Available from: http://www.vqronline.org/printmedia.php/prmMediaID/9169.

[45] Sorrell JBJ, Marcela R. An exploratory study of constructions of masculinity, sexuality and HIV/AIDS in Namibia, Southern Africa. C Cult Health Sex 2005; 7(6): 585-98.

[46] Simbayi L. "Psychosocial and cultural determinants of HIV/AIDS in the SADC Region", HIV/AIDS in Southern Africa: A Review paper for the WK Kellogg Foundation. Cape Town: HSRC Publishers 2002 .

Received: December 15, 2008

(C) Renzaho and Pallotta-Chiarolli; Licensee Bentham Open .

This is an open access article licensed under the terms of the Creative Commons Attribution Non-Commercial License (http://creativecommons.org/licenses/by-nc/3.0/) which permits unrestricted, non-commercial use, distribution and reproduction in any medium, provided the work is properly cited. 